\section{Factors associated with Schistosomiasis control measures in Mwaluphamba Location, Kwale County, Kenya}

\author{
Ahmad Juma, ${ }^{1}$ Arthur K.S. Ng'etich, ${ }^{1}$ \\ Violet Naanyu, ${ }^{2}$ Ann Mwangi, ${ }^{2}$ \\ Ruth C. Kirinyet ${ }^{1}$ \\ ${ }^{1}$ Department of Epidemiology \& \\ Biostatistics, School of Public Health, \\ Moi University, Eldoret; ${ }^{2}$ Department of \\ Behavioral Sciences-School of Medicine, \\ Moi University, Eldoret, Kenya
}

\begin{abstract}
The study set out to investigate the factors associated with Schistosomiasis control measures in Mwaluphamba location of Kwale County. A descriptive cross-sectional study design was used. Mwaluphamba location was purposely sampled and simple random sampling was used to select 338 respondents in villages in each location. Structured questionnaires were used to collect data. A majority of the respondents were males $(60 \%)$, Muslim affiliated $(85 \%)$, aged 41 years and over $(39 \%)$ and most $(56 \%)$ of them had achieved at least a primary level of education. Results showed that $40 \%$ of the respondents were knowledgeable of health education as a service offered by health care providers to control Schistosomiasis. Male respondents and those of Islamic affiliation were five times (OR: 4.686) and three times (OR: 3.13) more likely to seek health education in comparison to their female counterparts respectively. Respondents' who had achieved at least a primary level of education and those that earned an income of above one thousand shillings significantly utilized mass treatment. Respondents with income levels below a thousand shillings were less likely to seek both health education and mass treatment compared to those with a higher income. In conclusion, there was a statistically significant association between respondents' socio-demographic factors and control measures for the infection. There is need for equal implementation of all control measures to overcome the socio-demographic barriers and to ensure effective control of Schistosomiasis infection.
\end{abstract}

\section{Introduction}

Schistosomiasis is considered one of the
Neglected Tropical Diseases (NTD) and it is second only to malaria as the most devastating parasitic disease. In Kenya, schistosomiasis is endemic with an estimated prevalence of between $5 \%$ to $65 \%$ affecting over six million people. ${ }^{1}$ Both Schistosoma mansoni and Schistosoma haematobium exist and are unequally distributed in several parts of the country. Schistosoma haemotobium is high in most parts of the coastal belt as well as the lake basin. It is prevalent in scattered foci and sometimes mixed with Schistosoma mansoni in Eastern, Central and Nyanza provinces with mixed infections existing on the shores of Lake Victoria. The vectors for Schistosoma mansoni and Schistosoma haemotobium in Kenya belong to species of snails of the genus Biomphalaria and Bolinus respectively. $^{2}$

Schistosomiasis may not be a major cause of mortality but it ranks highly as a cause of morbidity as assessed in hospital attendances as well as research that has been carried out in different parts of Kenya. $^{2}$ The prevalence of infection is increasing as a result of the water development programmes such as agriculture and recreational activities which encourage the establishment of snail vectors exposing communities to infected water. ${ }^{3}$

While the socio-economic impact including poor school attendance and performance is known, Schistosomiasis has not been given the attention it deserves and continues to be a health problem for many developing countries. ${ }^{2}$ Treatment of Schistosomiasis infection has been increasing from 12.4 million in 2006 to 33.5 million in 2010 depicting an upward trend in its prevalence since the year 2002 when universal declaration to control the disease was made. ${ }^{4}$ The universal control measure of using chemotherapy to treat school-aged children and populations at risk of the infection in endemic areas of Kenya has not bore much fruits compared to other parts of the world. This is attributed to lack of consistent access to vulnerable populations, late detection of infections and inconsistent supply of the praziquantel drugs for consistent treatment. $^{2}$

The coastal area of Kenya is a Schistosoma haemotobium endemic area causing Urinary Schistosomiasis which is a major public health problem in Kwale County of the coastal region. ${ }^{4}$ Kwale County had a prevalence rate of $70 \%$ amongst school-going children despite the tireless campaign efforts by Kenyan government and other Non Governmental Organizations (NGOs) towards prevention and control of Schistosomiasis. ${ }^{5}$ Current research shows that Urinary
Correspondence: Arthur Kipkemoi Saitabau Ng'etich, Moi University, P.O. Box 747030100, Eldoret, Kenya.

Tel.: +254710 890400 .

Email: arthursaitabau@yahoo.com

Key words: Schistosomiasis, Control Measures, Kwale County.

Contributions: AJ, research idea conception, study designing, data collection, analysis, and interpretation of data; AKSN, drafting and revising the manuscript and final review and approval of final version of manuscript for publication; VN, study design, interpretation of manuscript, revising manuscript and final approval of version to be published; AM, data analysis review, revising of manuscript and approval of the final version for publication; RCK, references check, revising of manuscript and approval of the final version for publication

Conflict of interest: the authors declare no potential conflict of interest.

Acknowledgements: We would like to express our sincere appreciation to the entire Moi University School of Public Health academic fraternity for their guidance and more importantly their extensive knowledge in this area of research which informed the study. A special thank you to the people of Mwaluphamba location for their participation in the study.

Received for publication: 23 June 2016.

Revision received: 2 December 2016

Accepted for publication: 21 December 2016.

This work is licensed under a Creative Commons Attribution 4.0 License (by-nc 4.0).

(C) Copyright A. Juma et al., 2017

Licensee PAGEPress, Italy

Healthcare in Low-resource Settings 2017; 5:6108 doi:10.4081/hls.2017.6108

Schistosomiasis has a prevalence rate of $45 \%$ in Tsimba location and above $80 \%$ among school-aged children and an average prevalence of $18.2 \%$ among adults in Mwaluphamba location of Kwale County. 3,6

Kenya Medical Research Institute (KEMRI) and the Kenyan government through concerted efforts have been implementing a mass treatment programme to control Schistosomiasis over a long period of time but the prevalence of the infection still remains high in Kwale County. The programme is focused on treatment of school-going children who are diagnosed with Schistosomiasis. ${ }^{3}$ It is probable that the programme has not been fully effective in achieving a significant reduction in the prevalence of the infection given lack of attention to the specific factors associated 
with the control of Urinary Schistosomiasis hence resulting to infection and re-infection of the population from time to time in the region.

Recent studies have advocated for use of an integrated approach to control Schistosomiasis infection since the mass chemotherapy approach has been implemented for several years and yet the disease continues to be of a public health concern to most health sectors in Sub-Saharan countries. $^{7}$ The current study gives in-depth insight on the factors affecting the available control measures of Schistosomiasis infection from the respondents' point of view. In this respect, the study will trigger further research focused on effectiveness of control measures of Schistosomiasis and encourage an integrated approach towards elimination of the disease in the region.

\section{Materials and Methods}

\section{Study population and design}

The study was conducted in Mwaluphamba location, Matuga SubCounty in Kwale County in the month of August, 2014. Mwaluphamba location is made up of ten villages and 2,848 households with an estimated population of 17,559 people. ${ }^{8}$ The study respondents were drawn from all the ten villages in the area. A descriptive cross-sectional study design was used and the target population comprised of all household heads aged eighteen years and over.

\section{Sample size and sampling techniques}

A sample size of three hundred and thirty eight respondents was determined in accordance with the Fisher's Formula. ${ }^{9}$ Kwale County and specifically Mwaluphamba location was purposively selected as the study area given Schistosomiasis high $(80 \%)$ endemicity in the region. Simple random sampling was used to recruit household heads in each village in the location using the formula described below. The sample size was then distributed amongst the ten villages as shown in Table 1.

The minimum calculated sample size for the study was three hundred and thirty eight respondents but up to three hundred and eighty four study respondents were included to cover for non-response. The heterogeneous sample size in each of the villages was as a result of the difference in the proportional distribution of the total number of households in the location.

\section{Data collection instrument and study procedure}

Respondents were interviewed using a structured questionnaire. The questionnaires were administered by the principal investigator and two other research assistants who were trained on administering the instrument. The questionnaires were in both English and Kiswahili languages. The latter being the common language used in Mwaluphamba location of Kwale County, hence questions were translated to Kiswahili to ease understanding for those respondents who could not comprehend in English. The first section of the questionnaire captured the socio-demographic data of the respondents such as their age, gender, educational level and religion status, while the second part inquired about the factors associated with the control measures for Schistosomiasis in the region. House to house interviews were con- ducted in the selected households according to the list of the households sampled in each village. A random list of YES's and NO's of the households was generated in each village and the number of YES's corresponded to the sample size of the study. In each household, the head of the household was required to randomly pick a piece of paper marked YES or NO. If the household head picked a paper marked YES, then an interview was conducted upon his/her consent. This was done until the desired sample size was reached. The questionnaire consisted of twenty questions and each of the respondents was interviewed for five minutes. The interviews were conducted with the heads of the household or a representative aged 18 years and above in the absence of the household head.

\section{Data analysis}

Data was coded and entered into the Statistical Package for Social Sciences (SPSS) software Version 20. Means and standard deviations were used for continuous variables, while frequency listings were used for categorical variables. Associations between the variables were analyzed using chi-square tests of independence and multiple binary logistic regressions at $95 \%$ confidence interval.

\section{Ethical consideration}

The researcher sought clearance from the relevant authorities including the Institutional Research and Ethics Committee of Moi University and from the local authorities in the study area. A detailed explanation of the aim of the research was given to the study respondents before consenting to participate in the study and confidentiality of the data obtained from respondents was upheld.

Table 1. Proportionate distribution of respondents in Mwaluphamba location.

\begin{tabular}{lccc}
\hline Villages & Households (HHs) & Proportion of Total No. of HHs & Distribution of sample size/village \\
Mtsangatamu & 115 & $4 \%$ & 14 \\
Burani & 430 & $15 \%$ & 51 \\
\hline Mlafyeni & 132 & $5 \%$ & 16 \\
Tserezani & 821 & $28 \%$ & 98 \\
\hline Maponda & 508 & $18 \%$ & 60 \\
Pande & 134 & $5 \%$ & 16 \\
\hline Kirewe & 163 & $6 \%$ & 19 \\
Miatsani & 197 & $7 \%$ & 23 \\
\hline Mirihini & 323 & $11 \%$ & 38 \\
Kajiweni & 25 & $1 \%$ & 3 \\
\hline Total & 2848 & $100 \%$ & 338
\end{tabular}




\section{Results}

A socio-demographic summary of study respondents is presented in Table 2 .

\section{Knowledge on control measures of Schistosomiasis}

Regarding respondents' knowledge on the control measures of Schistosomiasis infection, $154(40 \%)$ of the respondents reported to be aware of health education services as a measure of control, 16 (4.2\%) had knowledge of clinical treatment of the infection, while $38(9.9 \%), 13(3.4 \%), 17$ (4.4\%), $13(3.4 \%)$ and $133(34.6 \%)$ of the respondents reported having knowledge of mass chemotherapy, snail control, use of safe water for domestic use, proper sanitation and behavior change respectively as control measures of Schistosomiasis infection.

\section{Socio-demographic factors associat- ed with Schistosomiasis control measures}

As indicated in Table 3, it was evident that gender, age, religious status, education level and income levels of the respondents were significantly $(\mathrm{p}<0.05)$ associated with use of health education as a control measure of Schistosomiasis infection. As indicated in Table 4, respondents' education and income levels were the only significant $(p<0.05)$ variables associated with mass treatment as a control measure of Schistosomiasis infection.

Multiple binary logistic regression indicated that controlling for respondents' age, it was found that their religious status, income levels and gender were significant $(p<0.05)$ predictors of seeking health education as a control measure for Schistosomiasis infection (Table 5). Those of Islamic affiliation were three times (OR; $95 \%$ : 3.313; CI 1.433-7.661) more likely to seek health education as a control method compared to their Christian counterparts. While those with income levels of below Ksh.1000 were less (85.7\%) likely to use health education as a control method compared to those with income levels of Ksh.5000 and above. Male respondents were almost five times (OR; 95\%: 4.686; CI 2.655-8.269) more likely to use the method compared to the female respondents. On the other hand, controlling for respondents' education level, their income levels was found to be a significant ( $\mathrm{p}=0.001)$ predictor for use of mass treatment as a control measure for Schistosomiasis infection. Those with income levels of below Ksh. 1000 were less (OR;95\% CI: 0.461; $0.121-1.754)$ likely to use the mass treatment method compared to those with income levels of more than Ksh.5000.

\section{Discussion}

\section{Socio-demographic factors}

The study revealed that Mwaluphamba location is majorly a Muslim $(85 \%)$ dominated region with only $14 \%$ of them being of Christian faith and 1\% comprising of traditionalists. In Islamic culture one cannot undertake the obligatory prayers which are done five times a day without taking ablution using water. ${ }^{10}$ Therefore, those of Islamic faith come into contact with water more frequently exposing them to risks of Schistosomiasis infection. The community in the region mostly practiced crop farming

Table 2. Socio-demographic characteristics of respondents.

\begin{tabular}{|c|c|c|}
\hline Demographic characteristics of the respondents & Frequency( $n=384)$ & Percentage (\%) \\
\hline $\begin{array}{l}\text { Gender } \\
\text { Male } \\
\text { Female }\end{array}$ & $\begin{array}{l}231 \\
153\end{array}$ & $\begin{array}{l}60 \\
40\end{array}$ \\
\hline $\begin{array}{l}\text { Level of education } \\
\text { Primary } \\
\text { Secondary } \\
\text { College } \\
\text { No formal education }\end{array}$ & $\begin{array}{c}216 \\
26 \\
3 \\
139 \\
\end{array}$ & $\begin{array}{c}56 \\
7 \\
1 \\
36\end{array}$ \\
\hline $\begin{array}{l}\text { Religious Status } \\
\text { Muslim } \\
\text { Christian } \\
\text { Traditional }\end{array}$ & $\begin{array}{c}325 \\
56 \\
3\end{array}$ & $\begin{array}{c}85 \\
14 \\
1\end{array}$ \\
\hline $\begin{array}{l}\text { Age } \\
\qquad \begin{array}{l}18-24 \\
25-30 \\
31-35 \\
36-41 \\
\text { Over } 41\end{array}\end{array}$ & $\begin{array}{c}51 \\
73 \\
49 \\
62 \\
149\end{array}$ & $\begin{array}{l}13 \\
19 \\
13 \\
16 \\
39\end{array}$ \\
\hline $\begin{array}{l}\text { Occupation } \\
\text { Crop farming } \\
\text { Livestock keeping } \\
\text { Fishing } \\
\text { Mixed Farming } \\
\text { All the above } \\
\text { Civil Servant } \\
\text { Others sources of income }\end{array}$ & $\begin{array}{c}169 \\
1 \\
2 \\
169 \\
2 \\
9 \\
32\end{array}$ & $\begin{array}{c}44 \\
0.3 \\
0.5 \\
44 \\
0.5 \\
2 \\
8\end{array}$ \\
\hline $\begin{array}{l}\text { Income Level in Ksh.* } \\
\quad<1,000 \\
1,000-4,000 \\
5,000-10,000 \\
>10,000\end{array}$ & $\begin{array}{c}203 \\
161 \\
17 \\
3\end{array}$ & $\begin{array}{c}53 \\
42 \\
4 \\
1\end{array}$ \\
\hline
\end{tabular}

*\$1US Dollar=Ksh.101.09. 
(44\%) and mixed farming (44\%) while a few others practiced fishing $(0.5 \%)$. Farming and fishing which solely depend on water, puts the community continuously in contact with water, therefore predisposing them to Schistosomiasis infection. This was similar to findings in other studies which reported that the communities practicing water-related socio-economic activities are predisposed to the infection. ${ }^{11-14}$

Mwaluphamba location was a low income region with a majority $(53 \%)$ of the people earning less than a thousand shillings a month, therefore, falling below the poverty index category of earnings of less than USD \$1 per person per day. ${ }^{15}$ Respondents who had income levels of above Ksh.10, 000 were a very infinitesimal proportion $(1 \%)$ to have any significant influence in the community. With the high poverty levels in the region, those suffering from the Schistosomiasis infection had difficulties accessing and affording the available health care services and sustaining good living conditions. This finding agreed with that of another study which found out that people with low incomes found it difficult accessing and affording health care services. ${ }^{16}$

The study also found that females $(60.2 \%)$ were more at risk of Schistosomiasis infection compared to their male $(39.8 \%)$ counterparts consistent with other study findings. ${ }^{12,13,17}$ This was attributed to women being frequently in contact with water while undertaking their routine household roles, fetching water for domestic use and their involvement in farming activities. Therefore, these activities increased their risk of contracting Shistosomiasis in contrast to another reported study that found males were at increased risk. $^{18}$

\section{Schistosomiasis control measures}

The study found that about $63.5 \%$ of the community disposes off their human excreta by use of latrine facilities. This is below the required national standard of $83 \%$ latrine coverage to create herd immunity. ${ }^{19}$ This meant that the water sources in the area were not safe for domestic use due to the probable contamination by human feacal matter predisposing the community not only to Schistosomiasis infection but to other water borne diseases. This finding concurred with that of a study which reported poor sanitation as being a major cause of Schistosomiasis infections. ${ }^{19}$

Health education in itself was not an ultimate control measure of the infection because its success is influenced by peoples' knowledge and perception of the infection, knowledge of disease transmis- sion and symptoms presentation and the degree of disease burden. However, the current study found that a majority of people in the region were not knowledgeable of transmission of Schistosomiasis, hence making health education less effective in controlling the infection. Mass treatment being an effective control measure of reducing the endemicity of Schistosomiasis according to a study done in Tanzania, ${ }^{20}$ may not have been as effective in Mwaluphamba location as the mass chemotherapy programme being implemented in the region only targets school-aged children leaving out other vulnerable groups such as the adults and pre-school aged children. The World Health Organization (WHO) recommends that where the level of transmission of Schistosomiasis infection is above $50 \%$, then treatment should be repeated every year until the prevalence decreases to $5 \%{ }^{21}$ However, this is not the case in Mwaluphamba location where treatment is normally done once after several years which in essence may not be effective in controlling the infection and bringing down the disease prevalence. Other control measures of Schistosomiasis were less practiced by the people in the region such as proper water drainage of all stagnant water sources to destroy the breeding sites of the disease vectors.

Table 3. Socio-demographic factors associated with health education.

\begin{tabular}{|c|c|c|c|c|}
\hline Variable & No & Yes & Chi-square & P value \\
\hline $\begin{array}{l}\text { Gender } \\
\qquad \text { Male } \\
\text { Female }\end{array}$ & $\begin{array}{c}81(35.1 \%) \\
119(77.8 \%)\end{array}$ & $\begin{array}{c}150(64.9 \%) \\
34(22.2 \%)\end{array}$ & 67.283 & $<0.001$ \\
\hline $\begin{array}{l}\text { Age } \\
\begin{array}{l}18-24 \\
25-30 \\
31-35 \\
36-41 \\
\\
\text { Over } 41 \\
\end{array}\end{array}$ & $\begin{array}{l}36(70.6 \%) \\
42(57.5 \%) \\
22(44.9 \%) \\
30(48.4 \%) \\
70(47.0 \%)\end{array}$ & $\begin{array}{l}15(29.4 \%) \\
31(42.5 \%) \\
27(55.1 \%) \\
32(51.6 \%) \\
79(53.0 \%)\end{array}$ & 10.775 & 0.029 \\
\hline $\begin{array}{c}\text { Religious Status } \\
\text { Muslim }\end{array}$ & $154(47.4 \%)$ & $171(52.6 \%)$ & 19.455 & $<0.001$ \\
\hline $\begin{array}{c}\text { Fisher exact } \\
\text { Christian } \\
\text { Traditional }\end{array}$ & $\begin{array}{c}43(76.8 \%) \\
3(99.9 \%)\end{array}$ & $\begin{array}{c}13(23.0 \%) \\
0(0 \%)\end{array}$ & & \\
\hline $\begin{array}{l}\text { Level of education } \\
\text { Primary } \\
\text { Fisher exact } \\
\text { Secondary } \\
\text { College } \\
\text { No formal education }\end{array}$ & $\begin{array}{c}118(54.6 \%) \\
17(65.4 \%) \\
3(100 \%) \\
62(44.6 \%)\end{array}$ & $\begin{array}{c}98(45.4 \%) \\
9(34.6 \%) \\
0(0 \%) \\
77(55.4 \%)\end{array}$ & 7.834 & 0.036 \\
\hline $\begin{array}{l}\text { Income Level in Ksh.* } \\
\quad<1,000 \\
1,000-4,000 \\
5,000-10,000 \\
>10,000\end{array}$ & $\begin{array}{c}160(78.8 \%) \\
33(20.5 \%) \\
5(29.4 \%) \\
2(66.7 \%)\end{array}$ & $\begin{array}{c}43(21.2 \%) \\
128(79.5 \%) \\
12(70.6 \%) \\
1(33.3 \%)\end{array}$ & 133.395 & $<0.001$ Fisher exact \\
\hline
\end{tabular}




\section{Association between respondents' socio-demographic factors and}

\section{Schistosomiasis control measures}

The study found out that there was a statistically significant $(p<0.05)$ association between respondents' gender, religious status and income levels with the use of health education as a control measure of Schistosomiasis infection. This could be because those of Islamic affiliation tend to be in frequent contact with water as a routine practice before undertaking obligatory prayers as opposed to their Christian counter parts. Therefore, they were more likely to seek health education regarding water con- tact as a risk factor to water related diseases. This was similar to findings of a study done in Egypt. ${ }^{22}$ Male respondents on the other hand were found to be five times more likely to seek health education than the female respondents and this finding agreed with those of a similar study which reported men having attended more health education sessions than women. ${ }^{23}$ Respondents' income levels was also found to be significantly associated with health education as those earning less than a thousand shillings being less likely to seek health education as a control measure of Schistosomiasis infection. This contradicted findings of a study done in western Kenya where it was reported that those with low income levels suffered more from the infection and therefore sought health education as it was a free service offered to the community at no cost. ${ }^{19}$

\section{Conclusions}

The control measures for Schistosomiasis infection exist in the region included: Health education, snail control, case and mass treatment. There was a significant association between respondents' gender, religious status and income levels with health education as a control measure

Table 4. Socio-demographic factors associated with mass treatment.

\begin{tabular}{|c|c|c|c|c|}
\hline \multirow[t]{2}{*}{ Variable } & \multicolumn{2}{|c|}{ Mass treatment } & \multirow[t]{2}{*}{ Chi-square } & \multirow[t]{2}{*}{ P value } \\
\hline & No & Yes & & \\
\hline \multicolumn{5}{|l|}{ Gender } \\
\hline Male & 191(82.7\%) & $40(17.3 \%)$ & 2.803 & 0.094 \\
\hline Female & $136(88.9 \%)$ & $17(11.1 \%)$ & & \\
\hline \multicolumn{5}{|l|}{ Age } \\
\hline $18-24$ & $47(92.2 \%)$ & $4(7.8 \%)$ & 8.256 & 0.083 \\
\hline $25-30$ & $65(89 \%)$ & $8(11.0 \%)$ & & \\
\hline $31-35$ & $45(91.8 \%)$ & $4(8.2 \%)$ & & \\
\hline $36-41$ & $49(79 \%)$ & $13(21.0 \%)$ & & \\
\hline Over 41 & $121(81.2 \%)$ & $28(18.8 \%)$ & & \\
\hline \multicolumn{5}{|l|}{ Religious Status } \\
\hline Muslim & $272(83.7 \%)$ & $53(16.3 \%)$ & 3.259 & 0.171 \\
\hline Christian & $52(92.9 \%)$ & $4(7.1 \%)$ & & \\
\hline Traditional & $3(100 \%)$ & $0(0 \%)$ & & \\
\hline \multicolumn{5}{|l|}{ Level of education } \\
\hline Primary & $186(91.6 \%)$ & $30(13.9 \%)$ & 7.888 & 0.037 \\
\hline Secondary & $26(100 \%)$ & $0(0 \%)$ & & \\
\hline College & $3(100 \%)$ & $0(0 \%)$ & & \\
\hline No formal education & $121(80.6 \%)$ & $27(19.4 \%)$ & & \\
\hline \multicolumn{5}{|l|}{ Income Level in Ksh.* } \\
\hline$<1,000$ & $186(91.6 \%)$ & $17(8.4 \%)$ & 16.478 & 0.001 \\
\hline $1,000-4,000$ & $124(77 \%)$ & $37(23 \%)$ & & \\
\hline $5,000-10,000$ & $15(88.2 \%)$ & $2(11.8 \%)$ & & \\
\hline$>10,000$ & $2(66.7 \%)$ & $1(33.3 \%)$ & & \\
\hline
\end{tabular}

Table 5. Multiple binary logistic regression (health education).

\begin{tabular}{|c|c|c|c|c|}
\hline Variable & Regression coefficient ( $\beta$ ) & OR & $95 \%$ CI for OR & P value \\
\hline $\begin{array}{l}\text { Age } \\
\begin{array}{l}18-24 \\
25-30 \\
31-35 \\
36-41 \\
\quad \text { Over } 41\end{array}\end{array}$ & $\begin{array}{c}-0.323 \\
0.087 \\
0.656 \\
0.091 \\
-0.323\end{array}$ & $\begin{array}{l}0.724 \\
1.090 \\
1.927 \\
1.096 \\
0.724\end{array}$ & $\begin{array}{c}0.499 \\
0.295-1.779 \\
0.511-2.329 \\
0.782-4.751 \\
0.498-2.408 \\
0.295-1.779\end{array}$ & $\begin{array}{l}0.481 \\
0.823 \\
0.154 \\
0.820 \\
0.499\end{array}$ \\
\hline $\begin{array}{c}\text { Religious Status } \\
\text { Muslim }\end{array}$ & 1.198 & 3.313 & $1.433-7.661$ & 0.005 \\
\hline $\begin{array}{l}\text { Income Level in Ksh.* } \\
\quad<1,000 \\
1,000-4,000\end{array}$ & $\begin{array}{r}-1.947 \\
0.554\end{array}$ & $\begin{array}{l}0.143 \\
1.740\end{array}$ & $\begin{array}{c}0.046-446 \\
0.548-5.532\end{array}$ & $\begin{array}{c}<0.001 \\
0.001 \\
0.348\end{array}$ \\
\hline $\begin{array}{l}\text { Gender } \\
\text { Male }\end{array}$ & 1.545 & 4.686 & $2.655-8.269$ & $<0.001$ \\
\hline
\end{tabular}


of the infection. The study also observed that there was a significant association between mass treatment in the community and the respondents' income levels. In conclusion, it was clear that the differences in socio-demographic characteristics amongst the people of Mwaluphamba location influenced use of the available measures towards control of Schistosomiasis infection. We recommend that the ministry of health should formulate policies that ensure equal application of all the Schistosomiasis control measures to complement each other for effective control of the infection in the region. The county government through the ministry of health should encourage other stakeholders in the county to conduct further research on the treatment seeking behavior of the community, effectiveness of snail control measures and on drug efficacy. Future policy should design prevention campaigns to target places of worship for non-Muslims and women's groups and tailor health education to those identified as being at higher risk for disease.

\section{References}

1. Midzi N, Mtapuri Zinyowera S, Mapingure $\mathrm{M}$, et al. Knowledge, attitudes and practices of grade three primary school children in relation to Schistosomiasis, Soil transmitted helminthiasis and Malaria in Zimbabwe. BioMedical CentralInfectious Diseases 2011;11:169.

2. Kenya Medical Research Institute. Neglected diseases. (Kwale); 2010.

3. World Health Organization. Weekly epidemiological record 30 April No.18.Available at http://www.who.int/ wer.2010;85:157-164.

4. Kenya Medical Research Institute. Preliminary report of the 8 selective mass-chemotherapy of urinary schisto- somiasis in Mwachinga community of Kwale District, Coast Kenya. KEMRI; 2001.

5. Kenya Medical Research Institute. Neglected Diseases. Kwale: Kenya Medical Research Institute; 1994.

6. Njenga S, Mwandawiro C, Muniu E, et al. Adult population as potential reservoir of NTD infections in rural villages of Kwale district, Coastal Kenya: Implications for preventive chemotherapy interventions policy. Parasites Vectors 2011;4:175.

7. McManus D, Gray D, Ross A, et al. Schistosomiasis research in the Dongting Lake Region and its impact on local and national treatment and control in China. Negl Tropl Dis 2011;5:8.

8. Kenya National Bureau of Statistics. National Housing and Population Census 2009. Nairobi: KNBS; 2009.

9. Mugenda O, Mugenda A. Research methods: quantitative and qualitative approaches. Nairobi: African Centre for Technology Studies (ACT); 2003.

10. Al-Farsy AS. Holy Quran translation. Nairobi: The Islamic Foundation; 1991.

11. Aboagye I, Edoh D. Investigation of the risk of infection of urinary schistosomiasis at Mahem and Galilea communities in the Greater Accra Region of Ghana. West Afr J Appl Ecol 2009;1:15.

12. Ali H, Abkar T, Mohamed M. Schistosomiasis and soil-transmitted helminthes among an adult population in a war affected area, Southern Kordofan State, Sudan. Parasites Vectors 2012;5:133.

13. Essa T, Birhane Y, Mengistu E, et al. Current status of mansoni infections and associated risk factors among students in Gorgora Town, North west Ethiopia. ISEN Infect Dis 2013;2013:636103.

14. El Katsha S, Watts S. Gender, behavior, and health: Schistosomiasis transmission and control in rural Egypt. New
York and Cairo: American University in Cairo Press; 2002.

15. World Bank. World bank updates poverty estimates for the developing world. Washington, DC: World Bank Group; 2005.

16. Ugbomoiko S, Okoye I, Heukelbach J. Factors associated with urinary schistosomiasis in two peri-urban communities in Southern Western Nigeria. Ann Trop Med Parasitol 2010;104:409-19.

17. King C, Muchiri E, Ouma J. Dynamics and control of Schistosoma haematobium transmission in Kenya: an overview of the Msambweni Project. Am J Trop Med Hyg 2000;55:127-34.

18. Shati AA. Factors affecting the prevalence of human schistosomiasis in Aseer Region, Saudi Arabia. J Biol Sci 2009;9:8.

19. Mwinzi P, Montgomery S, Owapa C, et al. Integrated community-directed intervention for schistosomiasis and soil transmitted helminthes in western Kenya - a pilot study. Parasites Vectors 2012;5:182.

20. Uneke CJ. Soil transmitted helminthes infections and schistosomiasis in school age children in Sub-Saharan Africa: Efficacy of chemotherapeutic intervention since World Health Assembly Resolution. Tanzania J Health Res 2009; $12: 1$

21. World Health Organization. Prevention and control of Schistosomiasis, and soil transmitted helmithiasis. Geneva: WHO; 2002.

22. Farroq M, Nallah J. The behavioural pattern of social and religious watercontact activities in the Egypt-49 bilharziasis project area. Bull World Health Organ 1966;35:377-87.

23. Schmitt I. Schistosomiasis. The burden of disease and trends of intervention. International Health Practice; 2006. 